\title{
Vitamin C Supplementation Improves Pulmonary Tuberculosis Patients' Sputum Conversion During Intensive Phase Category I Treatment in Medan
}

\author{
Elok Ariyani Safitri ${ }^{1 *}$, Parluhutan Siagian1 ${ }^{1}$, Bintang Yinke Magdalena Sinaga1, \\ Putri Chairani Eyanoer² \\ ${ }^{1}$ Department Pulmonology and Respiratory Medicine Faculty of Medicine, \\ Universitas Sumatera Utara, Medan \\ ${ }^{2}$ Training research Advocacy and teaching (Epi-Treat) Unit, Universitas Sumatera Utara, Medan
}

\section{Corresponding Author: \\ Elok Ariyani Safitri | Department of Pulmonology and Respiratory Medicine, Faculty of Medicine, Universitas Sumatera Utara, Medan | elok.ariyani@yahoo.com}

Submitted: August $27^{\text {th }}, 2021$

Accepted: October $27^{\text {th }}, 2021$

Published: February $28^{\text {th }}, 2022$

Respir Sci. 2022; 2(2): 72-77

https://doi.org/10.36497/respirsci.v2i2.30

\begin{abstract}
Background: Many factors influence the success of the acceleration of Acid-Fast Bacilli (AFB) sputum conversion in the treatment of the intensive phase of pulmonary tuberculosis (TB). One of these factors is the nutritional status or nutrition of pulmonary TB patients. Through a fenton reaction, Vitamin $\mathrm{C}$ is known to be able to sterilize Mycobacterium tuberculosis. This study aims to determine the effect of giving vitamin $\mathrm{C}$ on the conversion of AFB sputum in the intensive phase of pulmonary TB treatment.
\end{abstract}

Method: This study was an inferential, quasi-experimental evaluation of the acceleration of AFB sputum conversion following vitamin $C$ supplementation in patients with category I pulmonary TB. The study group was separated into two groups: 40 TB patients getting Anti Tuberculosis Treatment (ATT) with vitamin C, and 40 TB patients receiving ATT with placebo. Every two weeks, AFB sputum was examined, and vitamin C levels were measured before and after two months of therapy.

Results: Conversion of AFB occurred sooner in the vitamin C group of pulmonary TB patients, with as many as 29 patients (72.5\%) experiencing conversion of AFB sputum at the end of the second week of therapy, whereas there was no conversion in the placebo group. At the end of the fourth week, all patients (100\%) given vitamin C showed AFB sputum conversion, whereas only eight patients (20\%) in the placebo group had conversion at the end of the fourth week of treatment. Vitamin C levels increased significantly in the group of pulmonary tuberculosis patients who received vitamin C supplementation.

Conclusion: Vitamin $C$ supplementation in the treatment of pulmonary TB can accelerate the conversion of AFB sputum, which is statistically significant.

Keywords: Mycobacterium tuberculosis, vitamin C, AFB sputum conversion 


\section{INTRODUCTION}

Pulmonary tuberculosis (pulmonary TB) is a direct infectious disease caused by TB germs, namely Mycobacterium tuberculosis (M. tuberculosis). In 2019, the incidence of tuberculosis in Indonesia was the $3^{\text {rd }}$ highest in the world after India and Tiongkok, contributing $8.5 \%$ of TB cases worldwide, with 92000 deaths per year in Indonesia, and an additional 4700 deaths from HIV TB. ${ }^{1}$

Active TB patients are often associated with lower nutritional status compared to healthy people. ${ }^{2}$ Micronutrient deficiencies and poor general nutritional status in active TB patients can suppress the cell-mediated immune system, which is the host's main defense against $M$. tuberculosis. ${ }^{3}$ Giving vitamin $\mathrm{C}$ to TB patients can improve nutritional status by increasing appetite ${ }^{4}$ and iron absorption, which are involved in fenton reactions. ${ }^{5}$

Vitamin C (ascorbic acid) is a watersoluble vitamin that belongs to a class of antioxidant vitamins that can inhibit the exchange of extracellular free radicals. Vitamin $\mathrm{C}$ functions as both an antioxidant and a pro-oxidant. The sterilization of vitamin $C$ has an antioxidant impact on $M$. tuberculosis culture. The capacity of vitamin C to sterilize $M$. tuberculosis cells is due to an increase in ferrous ion concentration, which causes an increase in ROS generation, lipid alterations, redox imbalances, and DNA damage. Vitamin C penetrates the cells of $M$. tuberculosis and converts ferric ions to ferro ions. Through the Harber-Weiss and Fenton reaction, it produces superoxide, hydrogen peroxide, and hydroxyl radicals when combined with oxygen. This ROS production will damage DNA, disrupt lipids, and disturb redox equilibrium. ${ }^{5}$

This is the groundwork for studying the impact of vitamin $C$ on the acceleration of the conversion value of AFB sputum in pulmonary TB patients with positive smear sputum in the intensive phase treament.

\section{METHOD}

The design of this study is quasiexperimental and was conducted in Medan in 2017 for six months. The study population included new cases of pulmonary tuberculosis in the intensive phase category I who were treated at $\mathrm{H}$. Adam Malik Medan Hospital, Balai Pengobatan Penyakit Paru (BP4) Medan, and several health centers in Medan who met the study's inclusion and exclusion criteria and were willing to participate in the study by signing an informed consent letter.

The subjects in this study were pulmonary TB patients with positive smear examination who had never been treated with anti tuberculosis treatment (ATT) before, aged 20 to 65 years, HIV-negative patients, no gastric and liver disorders, non-diabetic, did not use immunosuppressive drugs, and were not pregnant or breastfeeding. Patients with pulmonary TB were selected at random using inclusion/exclusion criteria. According to the sample size calculation in this study, there were 80 active pulmonary TB patients participating, and after a simple 
quota randomization was carried out in parallel studies, it was revealed that each 40 pulmonary TB patients were supplemented with vitamin C (500 mg Ester type $500 \mathrm{mg} /$ day) with standard tuberculosis treatment, while the second group was given placebo with standard tuberculosis treatment.

AFB sputum examination was carried out microscopically, which was examined every 2 weeks for 2 months of treatment, and vitamin $\mathrm{C}$ levels before and after 2 months of treatment were examined using ELISA techniques. Data were descriptively analyzed to determine the frequency distribution of research subjects based on their characteristics, and then inferentially analyzed to determine the difference in AFB sputum conversion after the administration of vitamin $C$ plus ATT versus placebo plus $A T T$. To find out the relationship between vitamin C levels and AFB conversion, the chi-square test can be used if it fulfills the requirements, and if not, an alternative test, namely the Wilcoxon Signed Ranked test, The collected data was processed and analyzed with $95 \%$ confidence intervals and significance levels of $\mathrm{P}<0.05$.

\section{RESULT}

The demographic characteristics of TB patients who received Vitamin $C$ with ATT and placebo with ATT were described in Table 1. Sex and age differences were not significant between the Vitamin $C$ and placebo groups.

Table 2 shows that AFB conversion in all patients $(100 \%)$ who were given vitamin
C supplementation occurred at the end of the fourth week of treatment, but only eight subject (20\%) in the placebo group with ATT. Conversion of AFB sputum continued until the end of the study, which was assessed every 2 weeks during the intensive phase of treatment. This study proves that there are significant differences $(P<0.05)$ after 8 weeks of vitamin $C$ supplementation.

Table 1. Demographic characteristics of subjects

\begin{tabular}{lcc}
\hline \multirow{2}{*}{ Characteristic } & \multicolumn{2}{c}{ Treatment } \\
\cline { 2 - 3 } & $\begin{array}{c}\text { Vitamin C } \\
\text { with ATT } \\
(\mathbf{n}=\mathbf{4 0})\end{array}$ & $\begin{array}{c}\text { Plasebo } \\
\text { with ATT } \\
(\mathbf{n = 4 0 )}\end{array}$ \\
\hline $\begin{array}{c}\text { Gender } \\
\text { Male }\end{array}$ & $28(70 \%)$ & $25(62.5 \%)$ \\
Female & $12(30 \%)$ & $15(37.5 \% \%)$ \\
Age & & \\
20-40 years & $19(47.5 \%)$ & $20(50.0 \%)$ \\
$40-60$ years & $18(45.0 \%)$ & $17(42.5 \%)$ \\
$>60$ years & $3(7.5 \%)$ & $3(7.5 \%)$ \\
Positivity of AFB & & \\
$1+$ & $24(60.0 \%)$ & $29(72.5 \%)$ \\
$2+$ & $14(35.0 \%)$ & $10(25.0 \%)$ \\
$3+$ & $2(5.0 \%)$ & $1(2.5 \%)$ \\
\hline
\end{tabular}

AFB conversion was found to be $100 \%$ (40/40) in the Vitamin C with ATT group and $20 \%(8 / 40)$ in the placebo group with ATT, described in Table 3, where the addition of Vitamin $C$ in TB management was more effective than giving ATT alone $(P<0.05)$.

Table 2. Treatment and AFB sputum conversion

\begin{tabular}{ccc}
\hline \multirow{2}{*}{ Characteristic } & \multicolumn{2}{c}{ Treatment } \\
\cline { 2 - 3 } & $\begin{array}{c}\text { Vitamin C } \\
\text { with ATT } \\
(\mathbf{n = 4 0 )}\end{array}$ & $\begin{array}{c}\text { Plasebo } \\
\text { with ATT } \\
(\mathbf{n = 4 0 )}\end{array}$ \\
\hline $\begin{array}{c}\text { Conversion AFB } \\
1^{\text {st }} \text { Month }\end{array}$ & $40(100 \%)$ & $8(20 \%)$ \\
$2^{\text {nd }}$ Month & $0(0 \%)$ & $32(80 \% \%)$ \\
Conversion AFB Based on & \\
2 weeks & $29(72.5 \%)$ & $0(0 \%)$ \\
4 weeks & $11(27.5 \%)$ & $8(20 \%)$ \\
6 weeks & $0(0 \%)$ & $25(62.5 \%)$ \\
8 weeks & $0(0 \%)$ & $7(17.5 \%)$ \\
\hline
\end{tabular}


Table 3. Treatment and the Conversion of AFB sputum in One and Two Months

\begin{tabular}{|c|c|c|c|c|}
\hline \multirow{2}{*}{ Treatment } & \multicolumn{2}{|c|}{ AFB Conversion } & \multirow{2}{*}{ Total } & \multirow{2}{*}{$\mathbf{P}$} \\
\hline & 1st month & 2nd month & & \\
\hline Vitamin C with ATT & $40(100 \%)$ & $0(0 \%)$ & $40(100 \%)$ & \\
\hline Plasebo with ATT & $8(20 \%)$ & $32(80 \%)$ & $40(100 \%)$ & 0,0001 \\
\hline Total & $48(60 \%)$ & $32(80 \%)$ & $80(100 \%)$ & \\
\hline
\end{tabular}

Note: Paired T-test

Table 4. Vitamin C Level Before and After 2 Months Treatment

\begin{tabular}{|c|c|c|}
\hline \multirow{2}{*}{$\begin{array}{c}\text { Mean } \\
\text { level of } \\
\text { vitamin C } \\
(\mathrm{ng} / \mathrm{dL})\end{array}$} & \multicolumn{2}{|c|}{ Treatment } \\
\hline & $\begin{array}{c}\text { Vitamin C with } \\
\text { ATT } \\
(n=40)\end{array}$ & $\begin{array}{c}\text { Placebo with } \\
\text { ATT } \\
(n=40)\end{array}$ \\
\hline Before & $73.39 \pm 25.53$ & $74.59 \pm 25.51$ \\
\hline After & $372.84 \pm 36.06$ & $161.66 \pm 35.79$ \\
\hline Difference & $299.45 \pm 31.56$ & $87.05 \pm 39.60$ \\
\hline$P$ & 0.0001 & 0.0001 \\
\hline
\end{tabular}

Note: Paired T-test

The results of the paired t-test analysis showed a significant difference in vitamin $C$ levels after 2 months of treatment in both groups $(P<0.05)$. But the increased in vitamin $\mathrm{C}$ level is higher in subjects with vitamin C supplementation than in subjects with placebo. In the vitamin C supplementation group, the difference in vitamin $C$ level before and 2 months after ATT was $299.45 \pm 31.36 \mathrm{ng} / \mathrm{dl}$ compared to $87.05 \pm 36.90 \mathrm{ng} / \mathrm{dl}$ in the placebo group (Table 4).

\section{DISCUSSION}

The characteristics of this study are based on age, namely 20-40 years old for 39 people. As many as 35 people, and aged $>60$ years, as many as 6 people. The most is in the age group $20-40$ years, with as many as 39 people (48.75\%). The sex in this study was more in men than in women, with $70 \%$ in the group given vitamin $\mathrm{C}$ and $62.5 \%$ in the group not given vitamin C.

Conversion of sputum AFB in the vitamin $C$ with $A T T$ supplementation group occurred in the second week was $72.5 \%$ and $0 \%$ in the placebo group with ATT. Conversion of AFB sputum continued until the end of the study which was assessed every 2 weeks during intensive phase treatment. This study proves that there are significant differences after 8 weeks of vitamin $C$ supplementation $(P<0.05)$.

A study by L. Susanto et al. found significant results for AFB sputum culture. In pulmonary TB patients who received vitamin $C$ supplementation in the second week, $6.1 \%$ had negative sputum cultures, whereas none in the control group hadIn six and eight weeks, $93.5 \%$ and $100 \%$ of TB patients with vitamin $\mathrm{C}$ supplementation had negative sputum cultures, compared to $54.8 \%$ and $83.9 \%$ in the control group. ${ }^{6}$ In this study, the administration of vitamin C significantly increased vitamin $C$ levels in both groups with vitamin $\mathrm{C}$ and placebo. The increase in vitamin $C$ levels, on the other hand, was greater in the group that received vitamin $\mathrm{C}$ supplementation.

A study in New Zealand in healthy populations found that plasma vitamin $\mathrm{C}$ levels increased to $>70 \mu \mathrm{mol} / \mathrm{L}$ from $<50$ $\mu \mathrm{mol} / \mathrm{L}(\mathrm{P}<0.001)$ in one week of vitamin $\mathrm{C}$ supplementation and continued to increase in vitamin $C$ status after a four-week intervention $(P=0.016)$. There was a $20 \%$ increase in the chemotaxic function $(P=0.041)$ and the oxidant generation 
function of neutrophil cells $(P=0.031)$ after the intervention of vitamin $C$ supplementation. ${ }^{7}$

In the body, vitamin $C$ functions in several metabolic processes, including: 1) as a cofactor for a number of hydroxylation reactions, 2) catalyst nitric oxide (NO) degradation of heparin sulfate, and 3 ) redox homeostasis in the mitochondrial respiration process. In vivo studies show that ascorbate concentrations in mammalian mitochondria can be increased by dietary supplements of vitamin $\mathrm{C}^{8}$

Several studies stated that antioxidants found low in TB patients are glutathione, ascorbic acid (vitamin C), and a-tocopherol (vitamin E). Low antioxidant levels are caused by insufficient intake in pulmonary TB patients and increased free radicals during the process of phagocytosis of M. tuberculosis. ${ }^{9,10}$

In pulmonary $\mathrm{TB}$ patients who receive treatment, one indicator of evaluating the progress of therapy is the determination of sputum conversion. Many factors influence the success of AFB sputum conversion in intensive TB treatment. ${ }^{11}$

One study found that one of the factors that influenced the success of AFB sputum conversion in intensive phase treatment was the patient's initial nutritional status when diagnosed with TB. ${ }^{2}$ This is because TB infection increases leptin production, which causes loss of appetite and decreased nutrient intake, resulting in a deficiency of calories and protein. ${ }^{11}$

The most frequent side effects from the administration of vitamin $\mathrm{C}$ are heartburn, nausea, and vomiting. In this study, it is very rare for us to find a complaint in the patients we gave supplemental vitamin C supplementation in the treatment of intensive pulmonary TB, perhaps because the vitamin $\mathrm{C}$ capsules given were slow in absorption in the body, thereby reducing side effects in patients.

In terms of the price per capsule, which is around two thousand rupiah per tablet of vitamin $\mathrm{C}$, the supplementation of vitamin $\mathrm{C}$ to $\mathrm{TB}$ treatment can be considered because cost-effectively accelerating the conversion of AFB sputum smear can break the chain of transmission in the community.

The findings of this study may be used by health professionals to offer additional vitamin $\mathrm{C}$ supplements to pulmonary TB patients in treatment, as well as by the health department to develop a policy including vitamin $\mathrm{C}$ into the treatment of pulmonary TB in the intensive phase.

The limitation of this study is that the number of subjects with an AFB 3+ sputum smear was less than those with an AFB 2+ or $1+$. Further research is needed with a larger number of AFB 3+ sputum smear subjects and better recording of side effects.

\section{CONCLUSION}

In pulmonary tuberculosis patients receiving category I anti-tuberculosis treatment during the intensive phase, vitamin $C$ supplementation can accelerate the conversion of AFB sputum. 


\section{REFERENCES}

1. World Health Organization. Global Tuberculosis Report 2020. Geneva; 2020.

2. Samuel B, Volkmann T, Cornelius $S$, et al. Relationship between Nutritional Support and Tuberculosis Treatment Outcomes in West Bengal, India. $J$ Tuberc Res. 2016;4(4):213.

3. Ahmad I, Srivastava V, Prasad R, Yusuf M. Deficiency of Micronutrient Status in Pulmonary Tuberculosis Patients in North India. Biomed Res. 2011;22(4):449-454.

4. Papathakis PC, Piwoz E. Nutrition and Tuberculosis: A Review of the Literature and Considerations for TB Control Programs.; 2008.

5. Vilchèze $C$, Hartman $T$, Weinrick $B$, Jacobs WR. Mycobacterium tuberculosis is extraordinarily sensitive to killing by a vitamin C-induced Fenton reaction. Nat Commun. 2013;4.

6. Susanto L, Siregar Y, Kusumawati L. Vitamin C supplementation improve the sputum conversion culture rate in pulmonary tuberculosis treatment while rifampicin susceptible. IOP Conf Ser Earth Environ Sci. 2018;125(1):012140.

7. Bozonet SM, Carr AC, Pullar JM, Vissers MCM. Enhanced human neutrophil vitamin C status, chemotaxis and oxidant generation following dietary supplementation with vitamin C-rich SunGold kiwifruit. Nutrients. 2015;7(4):2574-2588.
8. Mandl J, Szarka A, Bánhegyi G. Vitamin C: update on physiology and pharmacology. $\mathrm{Br} J$ Pharmacol. 2009;157(7):1097-1110.

9. Grobler L, Nagpal S, Sudarsanam TD, Sinclair D. Nutritional supplements for people being treated for active tuberculosis. Cochrane Database Syst Rev. 2016;2016(6).

10. Edem VF, Ige $\mathrm{O}$, Arinola OG. Plasma vitamins and essential trace elements in newly diagnosed pulmonary tuberculosis patients and at different durations of anti-tuberculosis chemotherapy. Egypt J Chest Dis Tuberc. 2015;64(3):675-679.

11. Yüksel I, Şencan M, Dökmetaş HS, Dökmetaş I, Ataseven $H$, Yönem Ö. The relation between serum leptin levels and body fat mass in patients with active lung tuberculosis. Endocr Res. 2003;29(3):257-264. 